\title{
UM OLHAR PARA A HISTÓRIA DO ENSINO DE MATEMÁTICA NO BRASIL: UMA PERCEPÇÃO NO AMAZONAS
}

\author{
A LOOK AT THE HISTORY OF MATHEMATICS TEACHING IN BRAZIL: A \\ PERCEPTION IN AMAZONAS
}

\section{UMA MIRADA A LA HISTORIA DE LA ENSEÑANZA DE LA MATEMÁTICAS EM BRASIL: UNA PERCEPCIÓN EM LAS AMAZONAS}

\author{
Rogério Jacinto de Moraes Júnior ${ }^{1}$ (i) ( \\ José de Alcântara Filho² \\ Evandro Luiz Ghedin ${ }^{3}$ (iD)
}

\begin{abstract}
RESUMO
O texto que apresentamos ressalta um pequeno fragmento da história do ensino da matemática destacando sua trajetória antes e durante a sua chegada ao Brasil até se fazer presente no Amazonas. Para conseguirmos subsídios necessários para tal escrita, fizemos uma pesquisa bibliográfica, documental e também fizemos uso de entrevistas. Essa busca nos mostrou uma interessante trajetória da Matemática, começando pela Europa, passando pelo Brasil, mais especificamente na região sudeste, até chegar ao Amazonas. Aqui, além da Universidade Federal do Amazonas (UFAM), posteriormente Universidade do Estado do Amazonas (UEA) outras instituições particulares possibilitaram, de certa forma, o desenvolvimento desta área do conhecimento em nosso estado e a formação de professores de Matemática.
\end{abstract}

Palavras-chave: Ensino de Matemática; História da Educação Matemática; Formação de Professores.

\begin{abstract}
The text presented here highlights a small fragment of the history of mathematics education, highlighting its trajectory before and during its arrival in Brazil until it was present in Amazonas. In order to obtain the necessary subsidies for such writing, we did a bibliographic and documentary research and we also used interviews. This search showed us an interesting trajectory of Mathematics starting in Europe, passing through Brazil, but specifically in the southeast region, until reaching Amazonas. Here, in addition to the Federal University of Amazonas (UFAM), later the State University of Amazonas (UEA), other private institutions made possible, in a certain way, the development of this area of knowledge in our state and the training of Mathematics teachers.
\end{abstract}

Keywords: Mathematics teaching; History of mathematics education; Teacher training.

\footnotetext{
${ }^{1}$ Mestre pelo PROFMAT polo UFAM. Professor Assistente na Universidade Federal do Amazona, Itacoatiara, Amazonas, Brasil. Endereço para correspondência: Rua Nossa Senhora do Rosário, 3863, Tiradentes, Itacoatiara, Amazonas, Brasil, CEP: 69103-128. E-mail: rogeriojr09@hotmail.com

${ }^{2}$ Mestre em Ensino de Ciências na Amazônia pela Universidade do Estado do Amazonas (UEA). Professor Assistente na Universidade do Estado do Amazonas (UEA), Manaus, Amazonas, Brasil. Av. Djalma Batista, 2470, Chapada, Manaus, Amazonas, Brasil, CEP: 69050-010. E-mail: jdfilho@uea.edu.br

${ }^{3}$ Doutor em Filosofia da Educação pela USP. Professor Titular-Livre da Faculdade de Educação da UFAM, Manaus, Amazonas, Brasil. Endereço para correspondência: Av. General Rodrigo Octávio, 1200, Coroado I, Manaus, Amazonas, Brasil, CEP: 69067-005. E-mail: evandroghedin@gmail.com
} 


\section{RESUMEN}

El texto aquí presentado destaca un pequeño fragmento de la historia de la educación matemática, destacando su trayectoria antes y durante su llegada a Brasil hasta su presencia en Amazonas. Para obtener los subsidios necesarios para dicha redacción, realizamos una búsqueda bibliográfica y documental y también utilizamos entrevistas. Esta búsqueda nos mostró una interesante trayectoria de las Matemáticas comenzando en Europa, pasando por Brasil, pero específicamente en la región sureste, hasta llegar a Amazonas. Aquí, además de la Universidad Federal de Amazonas (UFAM), más tarde la Universidad Estatal de Amazonas (UEA), otras instituciones privadas hicieron posible, en cierto modo, el desarrollo de esta área de conocimiento en nuestro estado y la formación de profesores de Matemáticas.

Palabras clave: Enseñanza de las matemáticas; Historia de la educación matemática; Formación de profesores.

\section{INTRODUÇÃO}

A preocupação maior desse texto refere-se às origens e desenvolvimento do ensino de Matemática no Brasil, bem como sua expansão no território brasileiro até chegar ao Amazonas. Entendemos que é necessário compreender os estágios de crescimento desta ciência, assim como seus avanços e recuos, até chegar à organização atual. Para tal estudo foi dado destaque aos fatos significativos e aqueles que contribuíram de forma predominante para a estrutura atual da Matemática no Brasil e no Amazonas.

A trajetória pensada para a escrita deste texto parte de uma pesquisa bibliográfica, documental e entrevistas com coordenadores da área de Matemática de instituições de ensino superior em nosso estado. A partir da leitura dos textos, da análise do conteúdo dos documentos obtidos e das entrevistas tivemos o suporte necessário para a produção textual aqui apresentado.

A pesquisa justifica-se pela importância em compreender os aspectos históricos e epistemológicos do ensino de matemática do Brasil, que perpassam pelo desenvolvimento e institucionalização dos cursos de formação de professor de matemática no Brasil, especificamente a formação de professores de Matemática no Amazonas. Essa temática, formação de professores, é muito discutida no meio acadêmico e muito debatido por meio de publicações no âmbito da Educação Matemática. Para uma melhor abordagem, traz-se o seguinte problema de pesquisa: como as instituições foram organizadas para o desenvolvimento do ensino de matemática na Europa e no Brasil? Como esse movimento foi refletido no estado do Amazonas?

$\mathrm{Na}$ tentativa de responder e nortear a pesquisa em questão, nomeia-se o seguinte objetivo geral: estabelecer uma cronologia que indique o desenvolvimento e institucionalização 
do ensino de matemática no Brasil, e em particular, no Amazonas. E como objetivos específicos tem-se: a) descrever um panorama do estudo e ensino de matemática na Europa, enfatizando esse movimento em Portugal, um dos principais influenciadores da educação no Brasil; b) identificar o desenvolvimento das instituições de ensino de matemática no Brasil, destacando as correntes vigentes; c) destacar os fatos legais e pedagógicos que contribuíram na institucionalização da formação de professor de matemática na Universidade Federal do Amazonas.

Para uma melhor organização textual, ele foi dividido em três tópicos: no primeiro destacamos o período que antecedeu a chegada da Matemática no Brasil; no segundo, ressaltamos a chegada desta ciência em nosso país, bem como, seu desenvolvimento, e, no terceiro, abordamos sobre a chegada ao Amazonas. Finalizamos com algumas considerações referentes a esse histórico, assim como as contribuições desta área do conhecimento para o desenvolvimento da nação.

Ao buscarmos as origens da Matemática no Brasil, necessariamente chegamos à Europa, passando pela criação de algumas universidades, em particular, a Universidade de Lisboa, em Portugal, ressaltando principalmente a influência desta instituição de nível superior e sua influência em relação à chegada dos primeiros rudimentos das ciências exatas superiores em nosso país.

Em relação à chegada da Matemática ao Brasil, destacaremos as causas que tiveram como consequências o desenvolvimento do Brasil e o avanço educacional de nosso país, como também a busca pela criação das instituições de nível superior, bem como o desenvolvimento e evolução das ideias referentes aos processos de ensino e aprendizagem.

Na última parte deste texto damos um destaque todo especial ao início dos estudos matemáticos superiores no estado do Amazonas, passando pela criação da Universidade do Amazonas (UA) e posteriormente pela expansão da oferta de cursos de licenciatura desta área do conhecimento, tendo como movimento central a criação da Universidade do Estado do Amazonas (UEA) e demais instituições particulares do nosso estado.

\section{REFERÊNCIAL TEÓRICO}

Existem vários aspectos que compõem o entendimento da formação de professor, um deles perpassa pela compreensão dos processos históricos, nos mais variados e ricos entendimentos que compõem a historiografia, que tem como espaço de pesquisa documentos 
oficiais, livros, pergaminhos, atas, decretos, etc. Esses espaços propiciam informações que são transformadas em conhecimentos e saberes, que de maneira dialética nutrem profissionais e práticas do passado com as dos dias atuais. Como Burke (2016) relata através de uma metáfora de Claude Lévi-Strauus, a informação é algo primário, o cru, e o conhecimento é algo preparado, o cozido. Os dados são considerados e processados por mentes humanas, que são carregadas de subjetividades, suposições e preconceitos.

Fazer uma pesquisa com base histórica é um processo que requer muito cuidado e discernimento, para que não seja apenas uma narrativa de acontecimentos da história, que também tem sua importância, mas a função de um texto historiográfico, segundo Chartier (2002) não é apenas profetizar a história, mas é de um olhar voltado para trás compreendendo os significados e efeitos das rupturas, mesmo que mínimas e desiguais. Isso acarreta em novas perspectivas, uma nova modalidade de composição e de apropriação do escrito. O caminho histórico é mais sensato, por ser mais bem informado.

Pode-se pensar "a História é a ciência do passado", mas como afirma Bloch (2001) é um pensamento contraditório, porque a própria ideia de passado como objeto científico é absurda, sem uma observação prévia as características comuns aos fenômenos não podem ser feitas. Então uma análise historiográfica traz à luz a materialização de um conhecimento racional, uma comunicação com os elementos contemporâneos. A história é uma ciência, que tem como um dos seus predicados ser poética, ela não obedece a leis, estruturas ou abstrações.

Especificando ainda mais no campo da historiografia, esse trabalho ganha maior status dentro da História da Educação Matemática, do que na História da Matemática. Visto que, a primeira está voltada para as dinâmicas da constituição de um saber profissional, preocupandose nas discussões histórico-epistemológica da constituição da matemática escolar; já a segunda, está voltada mais para o campo didático, vezes como um recurso, vezes como uma metodologia (VALENTE, 2013).

\section{ASPECTOS METODOLÓGICOS}

São muitas as discussões sobre metodologia, métodos e procedimentos, como ressalta Mattos (2020, pg. 45), "alguns autores não fazem distinção entre método e metodologia por entenderem que ambas abordam aspectos semelhantes, outros tratam-na como base teóricometodológica". Esse movimento não é diferente na história da educação matemática, como questiona Valente (2007, pg. 28), “Qual metodologia para a história da educação matemática?”. 
Valente encontrou uma boa medida para fundamentos metodológicos nas práticas dos historiadores nas obras do professor e historiador Antoine Proust, especificamente no livro, de 1996, sob o título Douze lecons sur l'histoire.

\begin{abstract}
Esses historiadores não consideram que os fatos históricos estivessem prontos desde o início. Ao contrário, dedicam seu trabalho, em grande parte, à explicação de como eles deveriam ser construídos. No entanto, uma vez construídos, permaneceriam fatos definitivamente. Essa é a origem da idéia do trabalho histórico em dois tempos e entre dois grupos de profissionais: os professores e os pesquisadores. Os primeiros utilizam os fatos construídos pelos segundos. (Prost, 1996, p. 56).

A alteração sofrida nessa perspectiva da escola metódica, de construção definitiva dos fatos históricos, porém, não modificou a posição fundamental destes no discurso histórico. Desde Langlois e Seignobos até Annales, o lema comum da profissão é o de tê-los como elementos fundamentais da história. No entanto, uma vez estabelecidos, eles deverão ou não resistir à contestação, dentro do que pratica o historiador contemporaneamente. Permanece, desse modo, a regra de ouro da produção histórica: nada de fazer afirmações sem provas, isto é, não há história sem fatos (VALENTE, 2007, p. 31).
\end{abstract}

Inicialmente, foram selecionados livros que dispõe de informações sobre a constituição da história da educação matemática, a partir de movimentos religiosos, políticos e intelectuais que influenciaram o ensino de matemática na Europa e no Brasil. Faz-se, também, uma discussão com autores que compõem a literatura da história da educação matemática no Brasil. Para investigar o desenvolvimento dos estudos e ensino de matemática no Amazonas, procurouse a Universidade Federal do Amazonas, por ser a mais antiga instituição de formação superior, e posteriormente a Universidade do Estado do Amazonas, bem como algumas instituições particulares. Foi realizada uma entrevista com alguns professores, um deles o professor, Dr. Nilomar Vieira de Oliveira, que recomendou a leitura da dissertação de mestrado de Maria dos Remédios Gomes da Silva, com o título: Alguns Episódios da Educação Matemática em Manaus nas décadas de 1960 e 1970. Também, disponibilizou o texto inédito do saudoso professor Dr. Ivan de Azevedo Tribuzy (1938-2014). Deste modo, estabeleceu-se uma cronologia a partir dos dados coletados, os quais constituíram objeto de análise neste estudo.

\title{
4 APRESENTAÇÃO E ANÁLISE DOS DADOS
}

\subsection{Antecedentes à Chegada da Matemática no Brasil: O Que Sabemos?}

Para uma melhor compreensão de como a Matemática chegou ao Brasil faz-se necessário um estudo sobre os acontecimentos que antecederam a chegada desta ciência em nosso país. Os primórdios da Matemática em nosso país, desde a origem até aos dias atuais, 
foram frutos de reflexões e discussões que surgiram em ambientes externos, quase sempre nos Estados Unidos da América ou na Europa. Antes de chegar a nossa nação o ensino de Matemática passou por estágios que culminaram com o surgimento das Universidades europeias.

A criação e organização das primeiras Universidades na Europa, segundo Silva (2003), foi reflexo de um momento singular de entusiasmo pelas coisas da educação, circunstância essa que foi marcante para o desenvolvimento intelectual e social do homem. Esse acontecimento desencadeou uma onda de criação de centros de estudos na Europa, passando por Portugal e, posteriormente, chegando ao Brasil.

A criação e organização das universidades de Bologna (Itália), Paris (França), Oxford e Cambridge (Inglaterra), Lisboa (Portugal) e Valência (Espanha) segundo Araújo (2014), embora inicialmente mantivessem um forte vínculo religioso, também atendeu as expectativas da elite da época, pois proporcionou o desenvolvimento e disseminação das ideias renascentistas e a consolidação dos alicerces da nova revolução educacional, que causaria profundas transformações culturais e sociais, representando um novo marco na história da humanidade.

O enlace religioso das universidades europeias e consequentemente sua influência em Portugal é destacada por Silva (2003, p. 2-3) ao mencionar que,

\begin{abstract}
A partir do reinado de Carlos Magno, ampliou-se no Velho Continente a criação das escolas religiosas [...]. Em 1072, a catedral da cidade de Braga já possuía uma dessas escolas e, em 1127, a catedral da cidade de Coimbra também já possuía uma escola religiosa [...]. Passaram a ser criados, então, os lugares de instrução, que, de modo geral, funcionavam fora das igrejas locais. Onde quer que houvesse um bom mestre, juntavam-se os discípulos, criando, dessa forma, um centro de estudos [...].
\end{abstract}

O vínculo religioso das primeiras instituições de ensino fica evidente quando o prestígio da escola passava pela autorização papal, ou seja, uma espécie de credenciamento. Com essa atitude, segundo Silva (2003) a Igreja tentou direcionar e manter sob seu controle o surgimento da "elite intelectual no mundo ocidental" (p.3). Sabemos que esse plano só funcionou inicialmente e que posteriormente a autonomia intelectual foi reprimida com outras formas de persuasão e repreensão por parte da igreja (Inquisição), período esse que Miorim (1998) chamou de "estiagem"; ou seja, momento histórico em que as ideias científicas ficaram estagnadas.

Segundo José Esteve apud Silva (2003) dois acontecimentos paralelos modificaram o panorama da influência religiosa sobre o ensino na Europa. O primeiro diz respeito ao decreto 
do rei Frederico Guilherme II que tornou obrigatória a educação básica na Prússia, tirando a ingerência do clero. O segundo foi a Reforma Pombalina, quando o marquês de Pombal, primeiro ministro português de 1750 a 1777, expulsou os jesuítas de Portugal e de suas colônias.

Para Silva (2003) o século XIII foi o das universidades, devido ao surgimento de várias instituições. Nesse contexto surge a criação dos "Estudos Gerais de Lisboa", posteriormente, a Universidade de Lisboa que, com o tempo, foi transferida para a cidade de Coimbra. No mesmo período, os estudos da Matemática não estavam bem desenvolvidos na Europa Ocidental. Portanto, o ensino de Matemática na Universidade de Lisboa ficou relegado para o segundo plano. Somente com a criação da "Escola de Sagres", criada pelo Infante dom Henrique (13941460), que o ensino da Matemática em Portugal passou pelo processo de institucionalização.

De modo geral, o ensino e estudo da Matemática em Portugal, do século XV ao XVII, jamais esteve à altura do desenvolvimento dessa ciência em outros países da Europa Ocidental, como, por exemplo, na França e na Itália. Isso, de certa forma, explica o atraso que essa ciência teve em nosso país. O desenvolvimento científico de uma nação depende da vontade e dos interesses de seus governantes. Isso fica evidente nas palavras de Silva (2003, p. 6) quando declara que:

[...] em 1518 o rei dom Manuel I (1469-1521), conhecido pelo cognome de "O Venturoso”, empolgado com a chegada de Vasco da Gama à Índia e de Pedro Álvares Cabral ao Brasil, para impulsionar o desenvolvimento da ciência e da prática da navegação marítima, criou na universidade de Lisboa uma cadeira de Astronomia, na qual também se estudava a Matemática [...].

A familiaridade com a língua e o alto conceito em que eram tidos os bacharéis em Direito, tanto em Portugal como no Brasil, fizeram da Universidade de Coimbra o centro preferido pelos estudantes brasileiros. Segundo Castro (1992) os poucos estudantes brasileiros que foram estudar em Coimbra só tiveram a oportunidade de ter acesso às ideias de Descartes, Newton e Leibniz depois da reforma pombalina que criou, nessa Universidade, o curso matemático de quatro anos, com programas mais próximos dos estudos realizados pela Matemática até a primeira metade do século XVIII.

Desejo igual tinham os jovens brasileiros que ingressavam em Lisboa, na Academia Real de Marinha e os que obtiveram carta de oficiais engenheiros, depois de 1779, porque, somente a partir de tal data, foi introduzido o cálculo diferencial e integral nos respectivos programas, já no reinado de D. Maria I, "que se determinou a cuidar seriamente no adiantamento das sciencias navaes e militares". (CASTRO, p. 19). Enfim, Bacharéis em 
matemática pela Universidade de Coimbra, oficiais engenheiros e antigos guardas-marinha da Marinha de Portugal constituíram o grupo inicial de onde surgiram os primeiros professores de Matemática superior do Brasil.

Como vemos, para compreendermos como se deu a chegada do conhecimento matemático, seu ensino e desenvolvimento no Brasil devemos passar primeiro por sua história proveniente do velho continente. Entender suas raízes religiosas e seu atraso em relação aos demais países da Europa nos auxilia na percepção e na compreensão dos porquês em relação a essa disciplina em nosso país. Em relação ao ensino de Matemática o Brasil sempre foi dependente, quando não foi da metrópole, passou a ser dos demais países europeus desenvolvidos.

\subsection{A Matemática no Brasil: Chegada, Desenvolvimento e Consolidação}

Tanto Castro (1992) como Silva (2003) destacam que o ensino da Matemática no Brasil surgiu com propósitos missionários. As missões de padres jesuítas criaram as primeiras escolas. Ambos ressaltam que a origem dessas escolas foi o ano de 1549 na cidade de Salvador (Bahia). Assim surge a primeira escola de ler e escrever do país, logo, “o ensino de Matemática no Brasil começou com os jesuítas" (SILVA, 2003, p. 15).

Com a expulsão dos jesuítas do Brasil em 1759, Silva (2003) ressalta que teve início as chamadas aulas régias. Para Miorim (1998), com essa expulsão, o sistema educacional brasileiro virou um caos, pois essas aulas eram avulsas, isoladas e os professores selecionados não tinham uma formação adequada. Em relação às aulas régias de Matemática a frequência era tão baixa que o governador de São Paulo lançou o seguinte edital:

[...] todos os estudantes e pessoas conhecidamente curiosas se alistassem na aula que se havia de abrir para o ensino de geometria. Àqueles que, infringindo o determinado nesse edital, se não se apresentassem a alistar perante o Rev ${ }^{\mathrm{mo}}$. Padre Frei José do Amor Divino Duque, "aplicar-se-ia a pena de se sentar praça de soldado" (Nunes apud Miorim, 1998, p. 84).

Essa pressão e punição realizada pelo governo paulista deixa claro o desinteresse pelas aulas de geometria e mostra a visão autoritária que busca resolver os problemas pela força. Mais uma vez fica evidente que a atualidade, em relação aos estudos matemáticos, reflete as questões passadas. Miorim (1998) ressalta que apesar da resistência maior ser nas aulas régias de Matemática, isso não era um privilégio exclusivo desta área do conhecimento. De qualquer forma, o ontem e o hoje se interceptam mostrando uma realidade visível e evidente. 
Segundo Castro (1992) o ambiente tornou-se mais favorável a estudos matemáticos no Brasil somente com a vinda da corte portuguesa para o Brasil. Isso ocorreu, segundo Silva (2003), quando Portugal foi invadido pelo exército francês comandado por Napoleão Bonaparte (1769-1821) em 1807. A família real portuguesa fugiu com a corte para o Brasil, contando com a proteção da esquadra britânica. "Devemos, portanto, a Napoleão Bonaparte a verdadeira descoberta do Brasil por parte da metrópole, bem como a institucionalização do ensino superior" (SILVA, 2003, p. 32).

No Brasil D. João VI determinou a abertura dos portos às nações amigas (1808), fundou a Impressão Régia (1808), a Biblioteca Pública (1810) e, finalmente, pela Carta de Lei de 4 de dezembro de 1810, criou a Academia Real Militar, na cidade do Rio de Janeiro. Para Castro (1992) e Silva (2003) foi a partir da criação dessa academia que se desenvolveu o ensino da Matemática superior no país, pois a partir daí, o Brasil teve a primeira instituição destinada ao curso completo da ciência Matemática.

Não tendo sido criada no país, antes de 1934, qualquer instituição destinada ao ensino de Matemática superior, segundo Castro (1992), coube às escolas do Exército e da Marinha e às escolas de engenharia o importante papel de suprir esta falta, durante mais de cem anos. Dessa forma, o ensino da Matemática superior no Brasil passou, segundo Silva (2003) a partir de 1896 e até 1933, a ser ministrado exclusivamente como disciplina dos cursos de engenharia. O curso completo de sete anos, somente exigido dos oficiais engenheiros e de artilharia, constava de um curso matemático de quatro anos e de um militar de três.

Antes da fundação da Universidade de São Paulo (USP) em 1934, segundo Silva (2003) dois acontecimentos fortaleceram o desejo de criação de uma Universidade no Brasil. O primeiro foi a promulgação, pelo imperador dom Pedro I, da constituição do Brasil em 1824, nela, no art. $179^{\circ}$, em seu parágrafo 33 , previa a criação de uma Universidade. O segundo foi a promulgação da Lei Orgânica do Ensino Superior e do Fundamental na República, Decreto n ${ }^{\circ}$ 8659, conhecida como "Lei Rivadávia", que permitia, entre outras coisas, a criação de estabelecimentos de ensino superior pertencentes à iniciativa privada, instituindo, também, a livre docência no país.

Desde 1908, na fase áurea da produção da borracha no estado, se pretendia criar, em Manaus (Amazonas), uma instituição de ensino superior para a região. Nesse espírito, em 1909, parte da elite intelectual local aprovou os estatutos da Escola universitária Livre de Manaus. Em 1913, a instituição foi transformada em Universidade de Manaus. Os alunos pagavam uma 
taxa de mensalidade, porém as despesas das instituições eram cobertas pelos cofres públicos do Estado e do Município.

Depois da Constituição e da Lei Rivadávia houve, em vários estados brasileiros, a tentativa de criação de Universidades. Podemos destacar algumas como a do Paraná, Rio de Janeiro, Belo Horizonte. Todas essas tentativas não foram adiante, pois, segundo Silva (2003), aos poucos foram extintas as universidades criadas amparadas pelo Decreto $\mathrm{n}^{\circ} 8659$.

O desenvolvimento e direcionamento das ciências em nosso país, em particular da Matemática, não acompanhou, segundo Silva (2003) as principais correntes que fluíam naturalmente no Velho Continente e nos Estados Unidos da América do Norte. Ainda segundo o mesmo autor:

\begin{abstract}
Por toda a segunda metade do século XIX e nas duas primeiras décadas do século XX, predominou no meio intelectual brasileiro, a partir das escolas superiores, a ideologia positivista de Auguste Comte, com preceitos que balizaram a filosofia, a política e a ciência no Brasil. Sob a influência dessa ideologia, observa-se que o ensino da Matemática superior sofreu atraso e danos consideráveis, quando tomamos como referência o desenvolvimento da Matemática que ocorria no Velho Continente. (SILVA, 2003, p. 57-58)
\end{abstract}

Não satisfeito com a influência da ideologia positivista de Comte sobre o ensino da Matemática no Brasil, Oto de Alencar Silva (1874-1912), passou a fazer críticas e iniciou o que chamamos de ciclo de rupturas da influência de Comte sobre a elite intelectual brasileira. Para Castro (1992) Oto de Alencar teve o dom inestimável de saber despertar a curiosidade dos seus discípulos. Para ele ensinar era mais do que repetir conteúdos ou preparar os jovens para o mercado de trabalho. $\mathrm{O}$ que importava era desenvolver a inteligência e abrir a mente para as coisas superiores, portanto, o seu modo de ensinar era admirável e certamente renovou o estudo da Matemática.

Somente a partir de 1934, com a fundação da USP e de sua Faculdade de Filosofia, Ciências e Letras (FFCL), o ensino e desenvolvimento da Matemática passa por um segundo período de revolução, retornando com toda força ao nosso país, por meio de um curso próprio. Vale ressaltar que segundo Silva (2003) no período de 1811 a 1875, o ensino da Matemática superior no Brasil esteve limitado à cidade do Rio de Janeiro.

$\mathrm{Na}$ USP, teve início uma nova perspectiva para o ensino e desenvolvimento da Matemática superior fora das escolas de Engenharia. A comissão que criou a USP contratou na Europa, por intermédio do professor Theodoro Ramos, vários mestres para lecionar na FFCL. Para lecionar Matemática, Silva (2003) ressalta que em 1934 chegou a São Paulo, o matemático 
italiano Luigi Fantappié. Posteriormente, ainda sob a indicação de Fantappié, chegou para trabalhar na USP, em 1936, outro matemático italiano chamado Giacomo Albanese. Ambos, Fantappié e Albanese, impulsionaram, na época, o ambiente matemático em São Paulo e no Brasil.

O desejo por renovação e inovação em relação à Matemática fez a partir da segunda metade da década de 1930, houvesse reflexões mais profundas. Membros da comunidade matemática brasileira como Otto de Alencar, Manoel Amoroso Costa, Lélio Gama e Theodoro Ramos demonstraram preocupação em fazer pesquisa científica continuada. Esses nomes, assim como Júlio Cesar de Melo, estão na vanguarda em relação ao ensino e desenvolvimento da Matemática no Brasil.

Outro movimento que alavancou o desenvolvimento científico e matemático no Brasil foi a criação das sociedades científicas, A primeira que destacaremos é a Sociedade Brasileira de Ciências (SBC) fundada em 1916 no Rio de janeiro. Em 1921 essa sociedade passou a se chamar Academia Brasileira de Ciências (ABC). Na década de 1920, a ABC iniciou um profícuo programa de intercâmbio com cientistas e com instituições científicas estrangeiras, de modo que, ainda naquela década, viajaram para o Brasil, para realizar cursos e conferências, entre outros, os “cientistas Jacques Hadamard, Émile Borel, Paul Langevin e Albert Einstein" (SILVA, 2003, p.31).

Em 1948, com a participação de alguns membros da ABC foi criada a Sociedade Brasileira para o Progresso da Ciência (SBPC). Essas sociedades segundo Silva (2003) tinham por objetivo contribuir para o desenvolvimento científico e tecnológico do país. Em 1951, o presidente da República, Eurico Gaspar Dutra, criou por sugestão de uma comissão formada por membros da $\mathrm{ABC}$, o Conselho Nacional de Pesquisas (CNPq), atualmente Conselho Nacional de Desenvolvimento Científico e Tecnológico.

As sociedades científicas de Matemática também foram surgindo paralelamente às demais. A primeira delas foi a Sociedade de Matemática de São Paulo (SMSP), criada em 1945 no seio da USP e extinta em 1969, quando da fundação da Sociedade Brasileira de Matemática (SBM). Em 1952 foi fundado no Rio de Janeiro, como um órgão do CNPq, o Instituto de Matemática Pura e Aplicada (IMPA). A partir da década de 1960, segundo Silva (2003), houve um crescimento substancial na oferta e na demanda de cursos de graduação, licenciatura e bacharelado, em Matemática pelo país. Na década de 1980, foi fundada a Sociedade Brasileira de Educação Matemática (SBEM), que tem como objetivo congregar profissionais da área de Educação Matemática. 
A criação do IMPA alavancou a Matemática pura e aplicada no Brasil. Essa instituição foi uma das primeiras a criar programa de pós-graduação stricto sensu em Matemática, tendo início em agosto de 1964. Esse instituto foi responsável pelo desenvolvimento profissional de matemáticos de todo o Brasil que iam para lá em busca de continuar seus estudos em nível de mestrado e doutorado.

A produção científica e os eventos na área da Matemática têm possibilitado avanços significativos em relação a esse campo do conhecimento. Silva (2003, p. 156) destaca que:

\footnotetext{
Nos dias atuais, mais de vinte eventos científicos de nível internacional são realizados todo ano, em diversas instituições de nosso país. [...]. Em virtude da produção científica dos matemáticos brasileiros, em 1954 o Brasil passou a fazer parte do Grupo I na classificação de países membros da União Matemática Internacional. Em 1978, nosso país foi promovido ao Grupo II e, em 1982, ascendeu ao Grupo III, (o mais elevado é o grupo V), posição em que permanecia no início do século XXI .
}

Hoje há no Brasil inúmeros grupos de estudo e pesquisa e, a partir da criação dos programas de pós-graduação, stricto sensu, de mestrado e doutorado em Matemática, esse campo do conhecimento tem vislumbrado melhorias importantes em relação à qualificação de professores em nosso país. As Instituições de Ensino Superior (IES) de nossa nação têm travado uma batalha constante tendo em vista o avanço científico e crítico dos discentes. Sempre há possibilidade de melhoras nos cursos de licenciatura e bacharelado em Matemática das nossas IES.

\subsection{A Matemática no Amazonas: Início e Questões a Refletir}

Como mencionamos anteriormente, as primeiras tentativas de se criar uma Universidade em nossa região ocorreram em 1909 quando intelectuais aprovaram os estatutos da escola universitária livre de Manaus. Tribuzy (inédito) ressalta que a Universidade livre, teve origem por sugestão do Clube da Guarda Nacional, depois passou a se chamar Universidade de Manáos, tinha como objetivo manter os cursos das escolas do Exército Nacional. Nessa época, segundo Silva (2015) a capital do Estado do Amazonas, Manaus, ficou conhecida como a "Paris dos Trópicos" ou a "Paris das Selvas"; nesse período foi construído o porto flutuante, o Teatro Amazonas, o Liceu Provincial Amazonense e circulavam bondes elétricos, além de outras modernidades, como o telefone, o saneamento, etc.

Infelizmente, como muitas outras universidades que surgiram nesse período, a Universidade de Manáos foi quase toda desativada. Isso ocorreu, porque se tornou impossível sustentá-la, 
devido ao declínio econômico provocado pelo fim do ciclo da borracha no Amazonas. "Os cursos foram sendo extintos até a Instituição ser oficialmente encerrada em 1926” (TRIBUZY, inédito, sp.).

Podemos dizer que a Universidade de Manaós foi uma das primeiras do Brasil, mesmo que não houvesse um curso específico de Matemática, ela foi um embrião que, mais tarde, deu origem a Universidade Federal do Amazonas. Para Tribuzy (inédito) a história da Matemática no Amazonas teve início, de forma institucional a partir do ano de 1961, quando iniciaram as aulas da primeira turma do Curso de Licenciatura Plena em Matemática. Ele faz questão de ressaltar que:

[...] foram o Governador Gilberto Mestrinho de Medeiros Raposo e o Secretário de Educação e Cultura, Cônego Walter Gonçalves Nogueira que assinaram a Lei $n^{\circ} 71$, de 28 de dezembro de 1959, que criou o Curso de Licenciatura Plena em Matemática junto à Faculdade de Filosofia, que o próprio Cônego Walter havia fundado e era diretor. A autorização para o funcionamento do Curso de Matemática junto à Faculdade, foi estabelecida pelo Decreto $n^{\circ} 50.046 / 61$, de 24 de janeiro de 1961, assinado pelo Presidente Juscelino Kubitschek de Oliveira (TRIBUZY, inédito, sp.).

Os cursos oferecidos aos candidatos à Faculdade de Filosofia do Amazonas eram: Matemática, Pedagogia e Filosofia, obedecendo à legislação nacional vigente; diplomavam bacharéis e licenciados, no esquema conhecido como três mais um. Nesse esquema:

[...] excetuando o curso de Didática que deve ser feito na última série e em um ano, todos os demais currículos são de três anos, ao término dos quais os concludentes recebem o diploma de Bacharel, podendo lograr o diploma de licenciado no grupo de disciplinas do curso correlato, logo após o ano de Didática que, na ordem cronológica será no $4^{\circ}$ ano da escola (NOGUEIRA apud SILVA, 2015, p. 51).

A Universidade do Amazonas (UA) foi criada em 12 de junho de 1962 pela Lei Federal 4.609-A, de autoria do Deputado Federal Arthur Virgílio Filho, e oficialmente instalada em 17 de janeiro de 1965. É neste momento que nasce o Departamento de Matemática, órgão fundamental para o desenvolvimento da Matemática no Amazonas. Em 12 de fevereiro de 1976, o curso foi reconhecido pelo Decreto 77.138/76, assinado pelo Presidente Ernesto Geisel. A atual denominação de Universidade Federal do Amazonas (UFAM) veio com a Lei 10.468, sancionada pelo presidente Fernando Henrique Cardoso em 20 de junho de 2002.

Notamos, então, que foi a partir de 1961 que a Matemática no Amazonas começou a se desenvolver e dar os primeiros passos para a busca de um conhecimento mais profundo, planejado e sistematizado. Segundo Silva (2015) na primeira turma do Curso de Matemática 
foram matriculados nove alunos, mas apenas dois concluíram o curso. Os dois alunos formados, no ano de 1964, foram Waldner de Menezes Caldas e Dorval Varela Moura (já falecido). Os dois se tornaram docentes da Faculdade de Filosofia, como é relatado pelo Professor Ivan, aluno da segunda turma:

Quando o Dorval e o Waldner se formaram, logo foram professores da Universidade, do próprio Curso de Matemática. Por exemplo, o Waldner foi meu professor, deu aula de História da Matemática, já o Dorval foi professor do curso, mas em cálculo ou coisa desse tipo. Da mesma forma que aconteceu com eles, aconteceu com a gente. Eu me formei em 1965 e em $1^{\circ}$ de junho de 66 já era professor. Era Professor de Geometria superior (IVAN TRIBUZY apud SILVA, 2015, p. 56).

A demanda por docentes era tão grande que à medida que os alunos das primeiras turmas do curso concluíam seus cursos, eles iam assumindo as vagas das disciplinas que apareciam. "Poderiam ser vagas de novas disciplinas ou vagas nas disciplinas, as quais os professores que as ministravam precisavam se afastar" (TRIBUZY, inédito, sp.).

Durante certo período a quantidade de licenciados era menor que a demanda, portanto, os demais formados tinham uma vaga certa no mercado de trabalho, seja na Faculdade de Filosofia do Amazonas ou como professor de Matemática em diferentes escolas.

[...] até o ano de 1979, a quantidade de professores de Matemática com formação específica não era suficiente para atender às necessidades local. [...] dos 876 formados até aquele ano, apenas 95 eram "licenciados em Matemática", sendo que 26 deles estavam atuando "no departamento de Matemática", fazendo com que restasse apenas 69 para ocupar os espaços em escolas de ensino de primeiro e segundo graus da época, o que era insuficiente (FERREIRA apud SILVA, 2015, p. 56).

Percebemos pelos relatos de alguns docentes citados por Silva (2015) que as disciplinas da Matemática pura sempre foram enfatizadas, enquanto que as de cunho didático e pedagógico eram reduzidas e desprestigiadas. Outro fato a se considerar é que os docentes que iniciavam a carreira no ensino superior não possuíam nenhum estudo de Pós-Graduação, portanto, os conteúdos estudados na licenciatura não eram muito diferentes daqueles estudados no ensino médio para ciências exatas, então denominado curso científico.

Aos poucos os docentes do curso de Matemática iam saindo para cursar Pós-Graduação em outras instituições. Um destaque especial deve ser dado ao Instituto de Matemática Pura e Aplicada (IMPA), pois por lá passaram os primeiros professores em 1971 e voltaram cheios de entusiasmo. Tribuzy (inédito) ressalta que, além de complementar a formação, a Pós-Graduação proporcionou a aprendizagem de como funcionavam outras Instituições de Ensino Superior. 
A partir do aperfeiçoamento de vários docentes, segundo Tribuzy (inédito) foi criado em 1979 o Curso de Aperfeiçoamento em Matemática (CAM) em nível de pós-graduação (lato sensu), com objetivo de preparar os professores do Departamento e profissionais de outras instituições para o Curso de Mestrado em Matemática. Esse curso cumpriu os seus objetivos que eram: preparar novos professores para cursar o mestrado, encaminhar professores para o mestrado, estimular os professores já formados para a pesquisa e estudos de alto nível e aproximar os docentes com os de outros centros.

Em 1981, o Conselho Universitário através da Resolução nº 004/81, aprovou o Curso de Bacharelado em Matemática para funcionar, juntamente com a Licenciatura, sob a administração do Departamento de Matemática. Atualmente, além do Curso de Mestrado, o departamento de Matemática da UFAM oferece também o Curso de Doutorado na área de Geometria Diferencial em parceria com o Departamento de Matemática da Universidade Federal do Pará que oferece o Curso de Doutorado na área de Análise, aprovado pela CAPES em 2009.

Atualmente a Universidade Federal do Amazonas conta com cursos matutino e noturno na capital, e diversos cursos no interior do Estado. Além da UFAM, outras instituições de ensino superior criaram cursos de licenciatura em Matemática e contribuíram ou vêm contribuindo com a formação de professores no Estado do Amazonas. Entre elas destacamos a Universidade do Estado do Amazonas (UEA), Uninorte, Uninilton Lins, Escola Superior Batista do Amazonas (ESBAM) e o Centro Universitário de Ensino Superior do Amazonas (CIESA).

A Universidade do Estado do Amazonas (UEA) foi instituída através do decreto $\mathrm{n}^{\mathrm{o}}$ 21.666, de $1^{\circ}$ de fevereiro de 2001, autorizada pela Lei $n^{\circ} 2.637$, de 12 de janeiro de 2001, com a natureza jurídica de fundação pública, inscrita no Ministério da Fazenda sob o CNPJ n ${ }^{\circ}$ 04.280.196/0001-76, como uma instituição pública de ensino, pesquisa e extensão, com autonomia didático-científica, administrativa e de gestão financeira e patrimonial.

O credenciamento da UEA, na capital e no interior do Estado do Amazonas se deu pelo Conselho Estadual de Educação (CEE-AM), por meio da Resolução N. 006/01 - CEE-AM, de 17 de janeiro de 2001, e retificada pela Resolução N. 159/02 - CEE/AM, de 03 de dezembro de 2002. O acesso aos cursos de graduação se dá por meio do Concurso Vestibular e do Sistema de Ingresso Seriado (SIS) e a distribuição de vagas segue o estabelecido na Lei N. 2.894/2005 e normas aprovadas pelo Conselho Universitário (CONSUNIV).

O Curso de Licenciatura em Matemática, desde a sua implantação na Universidade do Estado do Amazonas ofereceu as seguintes vagas, por ano, pelo Processo de Vestibular. Vale 
ressaltar que no vestibular de 2001 os alunos ingressaram na Licenciatura em Ciências (Matemática e Física) e depois de concluídos dois períodos optaram pela licenciatura que preferiam.

\begin{tabular}{|c|c|c|c|c|}
\hline \multirow{2}{*}{ Ano } & \multicolumn{4}{|c|}{ Vagas } \\
\cline { 2 - 5 } & $\begin{array}{c}\text { Unidades Acadêmica } \\
\text { Escola Normal } \\
\text { Superior }\end{array}$ & $\begin{array}{c}\text { Centro de Estudos } \\
\text { Superiores de } \\
\text { Parintins }\end{array}$ & $\begin{array}{c}\text { Centro de Estudos } \\
\text { Superiores de } \\
\text { Tabatinga }\end{array}$ & $\begin{array}{c}\text { Centro de Estudos } \\
\text { Superiores de Tefé }\end{array}$ \\
\hline $2001^{*}$ & - & 100 & - & 100 \\
\hline 2002 & - & 100 & 50 & 50 \\
\hline 2003 & - & 50 & 50 & 50 \\
\hline 2004 & 45 & 50 & 50 & 50 \\
\hline 2005 & 47 & 50 & 50 & 50 \\
\hline 2006 & 45 & 50 & 50 & 50 \\
\hline 2007 & 90 & 50 & 104 & 50 \\
\hline 2008 & 42 & 52 & 50 & 50 \\
\hline 2009 & 45 & 52 & 100 & 50 \\
\hline 2010 & 80 & 52 & 50 & 50 \\
\hline 2011 & 80 & 52 & 100 & 50 \\
\hline 2012 & 80 & 52 & 50 & \\
\hline 2013 & 80 & 52 & & 50 \\
\hline
\end{tabular}

Quadro I: Oferta de vagas em licenciatura em Matemática (UEA)

Fonte: secretaria do curso de Matemática (ENS/UEA/2019)

O curso de licenciatura em Matemática, da capital, inicialmente funcionou apenas no turno matutino. Nos centros de estudos superiores de Parintins, Tabatinga e Tefé o curso iniciou funcionando nos turnos matutino e noturno. Atualmente, em Manaus o curso funciona nos turnos vespertino e noturno. Os cursos de licenciatura em Matemática que iniciaram nos municípios de Boca do Acre, Carauari, Coari, Eirunepé, Humaitá, Itacoatiara, Lábrea, Manacapuru, Manicoré, Maués, Presidente Figueiredo e São Gabriel da Cachoeira, são modulares e ministrados no turno da noite.

No caso das universidades particulares organizamos as informações em uma tabela na qual mostraremos a instituição, o ano de início do oferecimento do curso e o ano em que essa instituição de ensino superior suspendeu a oferta da licenciatura em matemática, quando esse for o caso:

\begin{tabular}{|c|c|c|}
\hline Instituição de Ensino Superior (IES) & Ano de início & Ano de suspensão \\
\hline Uninorte & 2003 & - \\
\hline Uni Nilton Lins & 2002 & 2012 \\
\hline ESBAM & 2000 & - \\
\hline CIESA & 2000 & 2004 \\
\hline
\end{tabular}

Quadro II: Período de início e suspensão de oferta de vagas em licenciatura em Matemática das instituições particulares do Amazonas

Fonte: Autores (2021) 
$\mathrm{Na}$ atualidade, a Uninorte e a ESBAM ainda mantém o curso de licenciatura em Matemática; já a CIESA e Uni Nilton Lins encerraram respectivamente em 2004 e 2012. É evidente que todas essas instituições têm contribuído para o aumento da oferta de curso de licenciatura em nosso estado, mas temos que refletir também, sobre a qualidade dos cursos ofertados, pois esse fato influencia diretamente na formação dos futuros professores de Matemática e consequentemente nos processos de ensino e aprendizagem nessa área do conhecimento em nosso estado.

\section{CONSIDERAÇÕES}

Através desse estudo bibliográfico, documental e das informações obtidas nas instituições podemos compreender como a Matemática chegou ao Brasil e o porquê de seu subdesenvolvimento em relação a outros centros como França e Itália. Percebemos também que o exagero no sentimento de autossuficiência fez com que o nosso país demorasse na busca pela colaboração de matemáticos estrangeiros e insistisse no autodidatismo.

Temos que admitir que foi necessária a ação interventiva de Napoleão Bonaparte para que a coroa portuguesa olhasse para a colônia brasileira. A chegada da matemática ao Brasil, portanto, foi consequência literalmente da pressão francesa e do auxílio da Inglaterra. O início e desenvolvimento do ensino de Matemática em nosso país também não foram fáceis, pois as aulas régias não despertaram o interesse nas pessoas, tendo que haver pressão das autoridades governamentais.

A busca pela criação de universidades no Brasil é outro ponto a se refletir, pois inúmeras foram as tentativas e também várias foram as frustrações. Aos poucos, o desejo instrucional foi se espalhando por todos os estados. A criação das sociedades científicas, grupos de pesquisas em ciências e Matemática e órgãos científicos institucionais foram de grande relevância para alavancar as pesquisas científicas em nosso país.

No Amazonas a criação da UA, posteriormente transformada em UFAM, foi o marco introdutório da Matemática em nosso estado. Essa instituição de ensino superior foi responsável pela formação dos docentes que iniciaram o ensino desta ciência nas escolas de Manaus. Além da UFAM, outra instituição pública tem fortalecido a formação dos futuros professores de Matemática, tanto na capital, como no interior, como é o caso da UEA. Não podemos deixar de 
falar das Universidades privadas que também têm contribuído para o desenvolvimento da ciência Matemática no Amazonas.

O desafio é gigantesco, pois além da oferta essas instituições dever garantir a permanência no curso, pois é grande o número de abandono e desistência. Além disso, a qualidade da formação oferecida é outro fato a se refletir, pois a ação docente está diretamente ligada com o conhecimento conceitual e cosmovisão adquiridos durante a formação. Se quisermos ensino de qualidade, devemos proporcionar uma formação inicial de excelência que passa por questões políticas, epistemológicas e metodológicas.

\section{REFERÊNCIAS}

ARAÚJO, Ulisses. Temas Transversais, pedagogia de projetos e as mudanças na educação. São Paulo: Summus, 2014.

BLOCH, Marc. Apologia da história, ou, O ofício do historiador. Rio de Janeiro: editora Zahar, 2001.

BURKER, Peter. O que é história do conhecimento. 1. ed. São Paulo: editora Unesp, 2016.

CASTRO, F. M. de Oliveira. A matemática no Brasil. Campinas, SP: editora da UNICAMP, 1992.

CHARTIER, Roger. Os desafios da escrita. ed. São Paulo: Editora UNESP, 2002.

MATTOS, Sandra. Conversando sobre metodologia da pesquisa científica. 1 . ed. Porto Alegre, RS: editora Fi, 2020.

MIORIM, Maria Ângela. Introdução à história da educação matemática. São Paulo: Atual, 1998.

SILVA, Clóvis Pereira da. A matemática no Brasil: história de seu desenvolvimento. 3 ed. Rev. São Paulo: Edgard Blucher, 2003.

SILVA, Maria dos Remédios Gomes da. Alguns episódios da educação matemática em Manaus nas décadas de 1960 e 1970. 2015. 159 f. Dissertação (Mestrado em Educação) Universidade Estadual de Campinas, Campinas, 2015. Disponível em:

http://repositorio.unicamp.br/jspui/handle/REPOSIP/254061. Acesso em: 24 abr. 2021.

TRIBUZY, Ivan de A. A história da matemática no Amazonas. Manaus: Inédito.

VALENTE, Wagner. O Lugar da Matemática Escolar na Licenciatura em Matemática. Bolema, Rio Claro/SP, v. 27, n. 47, p. 939-953, dez. 2013. https://doi.org/10.1590/S0103$\underline{636 X 2013000400012}$ 
VALENTE, Wagner. História da Educação Matemática: interrogações metodológicas. REVEMAT - Revista Eletrônica de Educação Matemática. v 2.2, p. 28-49, jan. 2007. Disponível em: https://periodicos.ufsc.br/index.php/revemat/article/view/12990/12091. Acesso em: 27/01/2021.

\section{NOTAS}

\section{AGRADECIMENTOS}

Agradecimento, em memória, aos professores Ivan de Azevedo Tribuzy e Nilomar Vieira de oliveira. Professores que tiveram uma contribuição significativa para o desenvolvimento da matemática no Amazonas.

\section{FINANCIAMENTO}

Não houve financiamento.

\section{CONTRIBUIÇÕES DE AUTORIA}

Resumo/Abstract/Resumen: Rogério Jacinto de Moraes júnior; José de Alcântara Filho Introdução: Rogério Jacinto de Moraes júnior; José de Alcântara Filho; Evandro Luiz Ghedin Referencial teórico: Rogério Jacinto de Moraes júnior; José de Alcântara Filho; Evandro Luiz Ghedin Análise de dados: Rogério Jacinto de Moraes júnior; José de Alcântara Filho; Evandro Luiz Ghedin Discussão dos resultados: Rogério Jacinto de Moraes júnior; José de Alcântara Filho; Evandro Luiz Ghedin Conclusão e considerações finais:Rogério Jacinto de Moraes júnior; José de Alcântara Filho; Evandro Luiz Ghedin Referências: Rogério Jacinto de Moraes júnior; José de Alcântara Filho; Evandro Luiz Ghedin Revisão do manuscrito: Rogério Jacinto de Moraes júnior; José de Alcântara Filho; Evandro Luiz Ghedin Aprovação da versão final publicada: Rogério Jacinto de Moraes júnior; José de Alcântara Filho; Evandro Luiz Ghedin

\section{CONFLITOS DE INTERESSE}

Os autores declararam não haver nenhum conflito de interesse de ordem pessoal, comercial, acadêmico, político e financeiro referente a este manuscrito.

\section{DISPONIBILIDADE DE DADOS DE PESQUISA}

Os autores declaram que disponibilizarão os dados utilizados na pesquisa (texto professor Ivan Tribuzy). Caso o leitor tenha interesse, entre em contato com a primeira autora. Também informam que os dados citados na pesquisa estão elencados nas referências, acompanhados dos seus devidos links de acesso.

\section{CONSENTIMENTO DE USO DE IMAGEM}

Não se aplica.

\section{APROVAÇ̃̃O DE COMITÊ DE ÉTICA EM PESQUISA}

Não se aplica.

\section{COMO CITAR - ABNT}

MORAES JÚNIOR, Rogério Jacinto; ALCÂNTARA FILHO, José; GHEDIN, Evandro Luiz. Um olhar para a História do Ensino de Matemática no Brasil: uma percepção no Amazonas. REAMEC - Rede Amazônica de Educação em Ciências e Matemática. Cuiabá, v. 9, n., 1, e21032, janeiro-abril, 2021. https://doi.org/10.26571/reamec.v9i1.11984

\section{COMO CITAR - APA}

Moraes Júnior, R.; Alcântara Filho, J.; Ghedin, E.L. (2021). Um olhar para a História do Ensino de Matemática no Brasil: uma percepção no Amazonas. REAMEC - Rede Amazônica de Educação em Ciências e Matemática, 9 (1), e21032. https://doi.org/10.26571/reamec.v9i1.11984

\section{LICENÇA DE USO}

Licenciado sob a Licença Creative Commons Attribution-NonCommercial 4.0 International (CC BY-NC 4.0). Esta licença permite compartilhar, copiar, redistribuir o manuscrito em qualquer meio ou formato. Além disso, 
permite adaptar, remixar, transformar e construir sobre o material, desde que seja atribuído o devido crédito de autoria e publicação inicial neste periódico.

\section{DIREITOS AUTORAIS}

Os direitos autorais são mantidos pelos autores, os quais concedem à Revista REAMEC - Rede Amazônica de Educação em Ciências e Matemática - os direitos exclusivos de primeira publicação. Os autores não serão remunerados pela publicação de trabalhos neste periódico. Os autores têm autorização para assumir contratos adicionais separadamente, para distribuição não exclusiva da versão do trabalho publicada neste periódico (ex.: publicar em repositório institucional, em site pessoal, publicar uma tradução, ou como capítulo de livro), com reconhecimento de autoria e publicação inicial neste periódico. Os editores da Revista têm o direito de proceder a ajustes textuais e de adequação às normas da publicação.

\section{PUBLISHER}

Universidade Federal de Mato Grosso. Programa de Pós-graduação em Educação em Ciências e Matemática (PPGECEM) da Rede Amazônica de Educação em Ciências e Matemática (REAMEC). Publicação no Portal de Periódicos UFMT. As ideias expressadas neste artigo são de responsabilidade de seus autores, não representando, necessariamente, a opinião dos editores ou da referida universidade.

\section{EDITOR}

Dailson Evangelista Costa (D)

\section{HISTÓRICO}

Submetido: 24 de março de 2021.

Aprovado: 14 de abril de 2021.

Publicado: 24 de abril de 2021 . 